\title{
International cooperation in astronomy before the IAU
}

\author{
Virginia Trimble \\ Department of Physics and Astronomy, University of California, Irvine CA 92697, USA \\ email: vtrimble@uci.edu
}

\begin{abstract}
I have written elsewhere from a (mostly) celebratory point of view about early international astronomical projects. This version looks at some of the same projects, but from a less cheerful point of view.
\end{abstract}

Keywords. Transit of Venus, Solar Eclipses, Carte du Ciel, Celestial Police

\section{Introduction}

The 19th century, particularly the second half, was an era of international activities across the board of human interests, including literally hundreds of meetings in the two decades before 1914, most in Paris, but Brussels, London, and even New York contributed. International astronomy actually preceded the 19th century and extended right up to 1914, with the IAU taking over in 1919, not without opposition from the countries and scientists who were initially excluded. See Trimble (2015) for one view of that extended landscape. Here I focus on a handful of initiatives, some less unsuccessful than others, including von Zach's Celestial Police, the BD, CD, and AGK catalogues, Astronomische Nachrichten and the Astronomische Gesellschaft, the Carte du Ciel and its competitors, and expeditions to observe solar eclipses and the transits of Venus (looking back to 1761 and 1769).

\section{The celestial police, $1800-01$}

The idea came from Franz Xaver von Zach (1754-1832), and the organizational meeting occurred at the observatory built for his own use by Johann Hieronymus Schröter (17451816), both of whom led complicated, interesting lives (Hockey et al. 2014). The idea was to patrol the plane of the ecliptic and find the planet that, according to the Titius-Bode "law" should come between Mars and Jupiter. I am indebted to Gudrun Wolfschmidt for the list of the 25 astronomers who were involved. Many were German, but Denmark, Austria, France, Sweden, Italy, Switzerland, Russia, and Britain were also represented. The idea was a sensible one - each was to patrol an assigned part of the ecliptic. Was it a success?

You could argue. Team member Guiseppe Piazzi indeed found Ceres, just at the start of 1800, before he knew about the project, and it was recovered by von Zach, using methods due to his student Gauss, after passing behind the Sun. Asteroid two, Pallas, was found by team member Wilhelm Olbers in 1802, number 3, Juno, by Karl Ludwig Harding of the "police", and number 4, Vesta, by team member William Herschel, from whom Schröter had acquired some of his early lenses, in 1807. Thirtyeight years then passed until Karl Hencke (1793-1866), who had been seven years old when the police convened, found numbers five, Astraea in 1845 and six, Hebe in 1847. Numbers now are recorded in six or seven digits and a complicated pattern that includes 
years of discovery and other information (not that you asked, but 1978VT8 is now 9271Trimble).

Much sadness came in between. In April 1813, retreating French troops first sacked and burned much of the town of Lilienthal, including the government office building where most of Schröter's astronomical and other papers were stored. Then they broke into the observatory and carried off or destroyed the most valuable clocks, telescopes, and other astronomical and mathematical instruments (Denning 1904 containing information from letters Schröter had written soon after the event). He attempted to write up those observations that had survived (a comet, and Mars), but his eyesight was failing, and he died soon after (Hockey et al. 2014).

\section{Some mid-century successes}

Heinrich Schumacher (1780-1850) was Danish by birth and spent much of his career either in Germany or in places disputed between those jurisdictions. In founding Astronomische Nachrichten in 1821 he offered to accept contributions in "any European language". One suspects he meant German, French, Italian, English, and, obviously, Danish, but, though there was an observatory at Tartu/Dorpat, I am not so sure about Estonian (or Basque). The journal still exists, the longest continuous astronomical publication. It went through a German-only period and is now (like most such things) primarily or exclusively in English.

The Astronomische Gesellschaft (Schielicke 2013) was, from its founding, until the Second World War by far the most international of the large astronomical societies, fewer than half its members coming from Germany from 1863 right up to 1939 (though with a large Austrian or Austro-Hungarian contingent). Early meetings took place in Vienna, Leiden, Stockholm, Genf, Brussels, Utrecht, and Budapest, and inter-war ones in Copenhagen, Budapest, and Bern. The membership is now 10-15\% foreign, about the same as the American Astronomical Society and less than the $30 \%$ or so for the Royal Astronomical Society. There have also been non-German officers, including Eddington in the years before he became IAU president. Post WWII meetings have occurred in Vienna, Prague, Graz, Innsbruck, and Basel. The 1914 and 1942 meetings were scheduled for St Petersburg and Rome, but were cancelled. Simon Newcomb was a member from 1873 until his death in 1909, and Edward Pickering from 1877 until his 1919 death, not to mention Franklin-Adams (1899-1912), Hale (1893-1938), Abetti (1897-1928), and John Couch Adams, an 1863 founder, along with Otto Wilhelm Struve, and... oh, MANY!

The catalogues: BD (Bonner Durchmusterung) was almost entirely the work of Friedrich Argelander (1799-1875). The southern equivalent, CD (from Cordoba), however, was begun by Benjamin Gould (1824-1896) and John Thome (1843-1908), invited to Argentina by president Domingo Sarmiento in 1870 to establish an observatory there. It was completed under Charles Perrine (1867-1951), another American, after his appointment as their successor as director in 1909 (Hockey et al. 2014). The observatory finally acquired an Argentinian director, Enrique Gaviola, in 1936. Periods of distrust between the US and Argentina (one caused by the Spanish-American War) and international financial crises drew out the CD process over very many years. Argelander also played a major role in the establishment of the Astronomische Gesellschaft and the society's 1869 decision to prepare a catalogue with accurate positions of all the BD stars brighter than $m=9$. This involved 16 observatories, four in the US and four others outside Germany, and eventually became AGK, completed in 1910. Successors continue down to the present time, with names like FK5, AGK3, etc., involvement of the US Naval Observatory, and eventual normalization to the HIPPARCOS (mostly European) satellite coordinates. 


\section{To the ends of the Earth: solar eclipse and transit of Venus expeditions}

Total eclipses of the Sun and transits of Venus are rare experiences, though for somewhat different reasons. From Earth, the Sun is eclipsed by the Moon a time or three per year, but the eclipse is total from only a very narrow strips of terrestrial surface and only for a few minutes. Transits of Venus can be seen from a large fraction of the world, but they occur typically in pairs, at most one pair per century (most recently 2004 and 2012). Transits of Mercury are commoner, but were expected to be less informative, and sometimes served as "practice events" for the Cytherean ones. Both eclipses and transits require reasonably cloud-free skies as well. Both were regarded as important in the 18th and 19th centuries, the eclipses for understanding the nature of the solar corona and other features visible only then, and the transits of Venus for accurate measurement of the length of the astronomical unit (semi-major axis of the Earth's orbit around the Sun).

What observations do you want? Obvious for solar eclipses - you look, and, once the devices exist, you photograph, take spectra, photograph the spectra, and measure polarization. For the transits, you measure precise times of the first, second, third, and fourth contacts, or as many as you can see. In advance, for the ToV AU determinations, you know the angular diameter of the Sun, the physical diameter of the Earth, and relative orbit speeds for the planets. Then time from first to third, or second to fourth, contacts of a ToV will tell you the linear diameter of the Sun. The same length, measured in both angular and linear coordinates, tells you the distance. This was the method invented by Halley (1656-1742) in 1677 (Sheehan and Westfall 2004). It requires that you be located somewhere where the entire transit is visible and the skies clear for up to six or more hours, and is really more complicated than this, but does not require that you know your longitude with enormous accuracy. Two observers at different latitudes are better than one. Joseph-Nicolas Delisle (1688-1768) suggested an alternative that makes use of, optimally, many observers, all of whom know their latitudes and longitudes very accurately and measure the time of the same contact, requiring less dire constraints on weather and on visibility of the entire event (it is, I think, the equivalent of measuring the heliocentric parallax of the Earth). Both methods were used, and Delisle in particular attempted to establish worldwide cooperation for the 1761 ToV event (Hockey et al. 2014).

Given that both the eclipses and the transits are, in effect, rare and unlikely to be optimally observable from your home observatory, one might have expected both to be opportunities for multinational expeditions. This is not, in general, what happened for either sort of event (Sheehan \& Westfall 2004; Cottam \& Orchiston 2015).

Admittedly, most astronomers preferred to observe from their home countries or, in those days of multiple empires on which the Sun never set, at least their colonies.

We have space here for only two sad anecdotes (Débarbat 2004) and one general campaign. The two 18th century transits were 1761 and 1769. Guillaume Le Gentil (1725-92) set out to observe the 1761 transit from Pondicherry, India, then a French colony, only to find it British by the time he arrived. He retreated towards the Ile de France of Mauritius, but was at some random point in the Indian Ocean, on a tossing ship, when the transit occurred on 6 June (though the sky was clear). He decided to remain in the east and wait for the 1769 event. So, after much wandering around, back to Pondicherry, once again French, only to be clouded out. He returned to France to find that he had been declared dead and his possessions handed over to his heirs. A bit Job-like, he acquired other assets, through a fortunate marriage and his writings, and "other sons and daughters" (well, actually one daughter) were given unto him.

Even sadder is the story of Abbé Chappe d'Auteroche and his associates. Session participant Curruty Jésus de Alba Martinez reminded us of the events during the session (though accidentally attributed them to the 1639 transit rather than the 1769 one). That 
transit was to be most readily observed from the western hemisphere. The British Royal Society had asked permission of Spain to send an expedition to Baja California (then part of "new Spain") and been turned down. A French application was granted, provided that two Spanish officers be included with the five Frenchmen. Servants brought the total number up to 28. It was clear; Chappe and one of the Spanish officers carried out the timing measurements independently; an epidemic began to spread; Chappe managed to hold out long enough to time a lunar eclipse a couple of weeks later, so as to establish their longitude. Others timed some occultations of Jovian satellites to improve that determination, and they "moved" San Jose del Cabo half a degree north and five degrees east. But additional members of the expedition died, including Chappe (a total of 21 of the 28) and only two of the French participants brought their data home.

Fast forward a century or so to the transit of 1874. Astronomers from 10 countries observed from one to 32 places per country. Britain with 30 not quite tying Russia at 32 (overall organization from O.W. Struve, whom we will meet again). E.A.B. Mouchez, not yet an admiral, but more than an able seaman, was at the Ile St-Paul. Others one might have heard of in other contexts include "Chinese" Gordon who was in the Sudan; Janssen who went to Japan; Secchi in India, Auwers in Egypt, and Seeliger in New Zealand. There was wide coverage and multiple nearby stations from both the same and different countries, because of guesses about where the clouds might be. None of the stations had officially more than one national sponsor (Sheehan \& Westfall 2004), though Gudrun Wolfschmidt has said she thinks there was some unofficial cooperation on-site.

Contemplating all this, Mouchez decided that it would make sense to convene an International Transit of Venus Conference in Paris in October 1881 to plan the best coverage for the 1882 event. Thirteen countries had delegates there; the most, of course, from France. Surprise, surprise, the United States sent no delegate, though it eventually deployed 11 expeditions, 6 in the US and 5 elsewhere, beaten only by Great Britain (12, many as promised at Paris), and France (13, more, and more places than promised). Russia, with neither ingress nor egress visible from home, opted out completely. Photography was also somewhat less popular than a few years before. French astronomers on the whole collected and collectively analyzed the data, but the AU or solar parallax remained much as before. The name "liquid drop effect" is given to the phenomenon that makes accurate timing of the contacts difficult to impossible, and photographic work has shown that it is not just an optical illusion, or an effect of the atmosphere of Venus.

What about eclipse expeditions? Similar things can be said about the 19th century ones. Many, going many places, but international groups rare enough that it was newsworthy when Norman Lockyer accepted an invitation from Benjamin Peirce to accompany the American expedition to Sicily in 1870 (Cottam \& Orchiston 2015).

Where are we today? The 2004 (mostly Eastern hemisphere) and 2012 (mostly Western hemisphere) Transits of Venus were no longer needed for solar parallax (now much better known from radar distances around the solar system), but were widely-marked events for education and public outreach. Indeed we had a student-provided observing station right outside the physics building for the 2012 event here at University of California, Irvine (yes, I looked, though I have never seen a total solar eclipse). As for recent eclipses, a very informative article by Pasachoff (2018) recounts the many educational activities from the ground along the path, mostly in the US, and also research undertaken from several satellites for the August 2017 event, not all American. The most fascinating thing in that article, not emphasized in the text and incorrectly described in the figure caption is an image of totality with the corona, prominences, and all suppressed so that you can see the Moon by earthshine. 
Another oddity, not much remarked upon by the experts, is that photographs of the various $\mathrm{ToV}$ and eclipse expeditions quite often include a few women at the eclipses (many but not all wives and other family members) but the ToV expeditions do not seem to.

\section{The Carte du Ciel and its competitors}

Admiral Ernest Amedée Barthéleḿy Mouchez (1821-1892), director at the Paris Observatory from 1878, whom you met back with the transits of Venus, was not the only person to realize that rapid advances in photography might make it possible to image the entire sky and thereby produce charts and atlases greatly superior to the existing ones. But he was the person who, with David Gill of the Cape of Good Hope Observatory, decided to organize a great many observatories and observers, in many countries, to do it. Both also had other astronomical achievements (Hockey et al. 2014).

In August, 1887, he gathered in Paris more than 50 astronomers from 20 observatories in 16 countries and persuaded them all to order roughly identical astrographic telescopes, about half from the Henri Brothers in Paris, the other half from Grubb in Ireland (the latter used by British and British colony observatories). The sky zones from north to south were Greenwich, Vatican (took the first plate, August 1911), Catania, Helsingfors, Potsdam, Hyderabad N, Uccle (took the last plate December, 1950), Oxford 1 and 2, Paris, Bordeaux, Toulouse, Algiers, San Fermando, Tacubaya, Hyderabad S, Cordoba, Perth (Edinburgh), Cape Town, Sydney, and Melbourne. Otto W. Struve of Poulkova assumed the presidency of the Astrographic Congress, which met again in 1896, 1900, and 1909.

As Alan Batten noted during the session in Vienna, Struve (1819-1905) had reservations almost from the beginning and expressed them in scathing letters to Gill and to Simon Newcomb in the US (whose Naval Observatory did not join in the project; nor did any other American institution). With hindsight we can see that the $2 \times 2$ deg $(16 \times 16 \mathrm{~cm})$ plates were going to take a very long time to cover the sky (the Palomar Observatory Sky Survey Plates, $14 \times 14$ inches, covered $6 \times 6 \mathrm{deg}$ ); emulsions were not yet very sensitive by 1950s standards; and there were no good standard stars to calibrate magnitudes in most of the sky, meaning that the proposed catalogues would be of limited utility.

The IAU took over the project as Commission 23 (Carte du Ciel) under the initial presidency of Herbert H. Turner (1861-1930) (Blauuw 1994). The Commission voted itself out of existence at Brighton, 1970 under the presidency of W. Dieckvoss and merged with Commission 24 (Stellar parallaxes and proper motions, President W.J. Luyten). Under mostly French presidents they had succeeded finally in finishing the printed Astrographic Catalogue. Defining plate constants, deriving proper motions, and so forth was to be left to the individual observatories. Recent articles on the Carte $d u$ Ciel have pointed out that the (mostly remeasured) plates serve as excellent first epoch data for proper motions from the Tycho (HIPPARCOS) catalogues. P. Lacroute, who would otherwise have become the next president of Commission 23 proposed a working group within C24 to take charge of the Astrographic Catalogue.

Meanwhile, as it were, London-born John Franklin-Adams (1843-1912) accomplished the first all-sky photographic atlas. Working from Godalming and Johannesburg, with a telescope of his own design and $15 \times 15 \mathrm{deg}$ plates, he managed nearly the whole sky in 206 charts, published after his death by the Royal Astronomical Society as the Chart of the Heavens (Hockey et al. 2014). Complete sets of the photographic charts were distributed to a few observatories and served as the basis for several catalogues.

Meanwhile, back in the United States, Hale was not yet 19; Lick under Edward Holden had just received its 36 -inch refractor in 1888; and the remaining big noise was 
Edward C. Pickering (1846-1919) of Harvard. He too wanted an all-sky survey, under his control. Prying $\$ 50000$ from Catherine Wolf Bruce (Lorillard tobacco money) he had constructed the Bruce astrograph, to use $13 \times 13$ inch, $5 \times 5$ deg plates (a better bet than Carte du Ciel, though not quite up to POSS standards). The southern sky was well imaged, first from Arequipa Peru, then from Bloemfontein South Africa. The various Luyten proper motion surveys were one of the products, and some of the images used by Henrietta Leavitt in studying variable stars in the Magellanic Clouds.

Pickering also attempted to establish US-led committees to standardize radial velocities, absolute stellar positions, and stellar magnitudes (Pickering 1885, 1889, 1890) without conspicuous success. But he did persuade the 1910 meeting of the Solar Union to adopt the OBAFGKM Harvard system of spectral types. Much more about his efforts can be found on various fairly obscure websites. His survey plates went down at least to $m=17$ in 3-hour exposures (rather similar to Franklin-Adams), and the astrograph lens has recently found its way back to Harvard and been installed as part of a museum display by Sara Schechner, their curator of astronomical instruments.

\section{Conclusions}

Well, what should we say? Like astronomical endeavours themselves, some of the cooperative initiatives worked well; others not. Was there any correlation of success with international collaboration, and has the ratio of successes to failures grown under the IAU? You be the judge.

\section{References}

Blaauw, A. 1994. History of the IAU, Dordrecht, Kluwer

Cottam, S. and Orchiston, W. 2015. Eclipses, Transits, and Comets of the Nineteenth Century, Springer

Débarbat, S. 2004. Venus Transits: A French View, in D.W. Kurtz, Ed. IAU Colloquium 196, 41 Denning, W. F. 1904. Observatory 27, 313

Hockey, T. et al. Eds. 2014. A Biographical Encyclopedia of Astronomers, 2nd Ed. Springer

Pasachoff, J. M. 2018. Astronomy \& Geophysics 59, 4.1

Pickering, E. C. 1885, Observatory 8, 51

Pickering, E. C. 1889, Sidereal Messenger 4, 43

Pickering, E. C. 1890, MNRAS 45, 125

Schielicke, R. E. 2013. Die Astronomische Gesellschaft und ihre Mitglieder 1863-2013 Hamburg, Astronomische Gesellschaft

Sheehan, W. and Westfall, J. 2004. The Transits of Venus, Amherst, New York, Prometheus Books

Trimble, V. 2015. Journal of the American Association of Variable Star Astronomers 43, 244 